\title{
Characteristics of Kenaf (Hibiscus cannabinus L.) Mutants Induced by Gamma-Ray
}

\author{
In-Sok Lee, Chan-Ho Kang, Suk-Ju Kwon and Young-Eun Na \\ Jeollabuk-do Agricultural Research \& Extension Services, Iksan City 54591, Korea
}

\begin{abstract}
Kenaf (Hibiscus cannabinus L.) is known as a multipurpose crop producing biomass for energy thus, the study was conducted to select the elite mutants with higher biomass produced through mutation. Obtained from the National Agricultural Genetic Resources Center (NAGRC) in Korea, the seeds of the original natural resource named IT202801 (control) were irradiated with 250 Gy gamma-ray. The agronomic performances, genetic variation and histological analysis of the elite mutant lines were investigated at $\mathrm{M}_{2}$ generation in comparison with the control. Significant differences were observed from the previous three evaluations of the eight mutants. Nine plants, including the control and eight mutants, had little difference in the number of flowering days from July 23 to July 25. The leaf shape of the control was entire, while the leaf shape of the mutant was palmate. Of the eight lines, $\mathrm{M}_{2}$ IT20-5 showed better performance in regard to diameter, dry weight and seed weight per plant. The random amplified polymorphic DNA (RAPD) analysis produced a genetic diversity of $72.7 \%$ within the genotypes used. A dendrogram was constructed based on the RAPD fragments. Differentiation was demonstrated between the control and kenaf mutants. Taken together, the mutant line, $\mathrm{M}_{2} \mathrm{IT} 20-5$, can be useful as a resource for high biomass production.
\end{abstract}

Key words: Kenaf, mutants, yield, RAPD.

\section{Introduction}

Kenaf (Hibiscus cannabinus L.), which belongs to the family of Malvaceae, is an annual $\mathrm{C} 3$ and a common warm season fiber plant native to India and Africa [1]. The chromosome number of kenaf is in the multiple number of 18 with $2 n=36$ to $2 n=180$ [2]. Although, kenaf is a tropical plant, its cultivars are now well adapted in a wide geographical and climatic range [3]. Kenaf plants have been widely used for the production of paper, biocomposites, fiber boards and bioplastics and as well as source of material in the textile industry. It is an important crop in many developed countries such as USA and Japan where it is being used for the production of fiber cordage and forages. Due to its promising growth, height and fiber content, kenaf was identified as a multipurpose crop producing biomass for energy and natural fiber for

Corresponding author: In-Sok Lee, Ph.D., research field: breeding.

Running title: Characteristics Evaluation of Kenaf Mutants industrial uses [4].

This plant was introduced in South Asia around 1900 , and in Korea in the 60's, however, it has limited use in the country. In recent years, its value in Korea has been increasing as it has been used as forage, and for biomass and fuel production. Researches on kenaf have been done by the different research institutions in Korea since 2003, which focus on the development of new varieties, agronomic practices and downstream application development studies such as animal feed $[5,6]$. To successfully cultivate kenaf in Korea, the development of its new varieties producing high biomass is essential. Unfortunately, the yield of an early maturing kenaf variety in Korea is still very low. The highest yields achieved for early maturing varieties were $14.8 \mathrm{t} / \mathrm{ha}$ and $16.1 \mathrm{t} / \mathrm{ha}$ only in Jeokbong and Jangdae, respectively, thus becoming a major limitation for commercial use [7]. Of all the available early maturing kenaf varieties, only a few were suitable to be planted in Korean climate. The late flowering kenaf plant variety has been identified as 
the most essential trait required for growing in Korea to increase biomass production. However, this variety was not able to bear seeds in Korean climate. Thus, in order to overcome the problem on the lack of varieties, the development of a new kenaf variety with selected target traits is imperative.

Genetic variability is a prerequisite for any successful breeding programme, and the creation and management of such induced variability, these then become a central base for the improvement of any crop species. Mutation induction is one appropriate way to develop a new variety with desirable traits in a short period of time compared to cross-breeding. Spontaneous mutation was not expected to serve effectively in the improvement of a crop due to its very low: $10^{-9}-10^{-7}[8]$. Nowadays, this technique has become popular to plant breeders who are into developing new varieties through generating and utilizing genetic variability in both chemical and physical mutagenesis [9]. Also, mutation induction becomes an effective tool to broaden existing germplasm and improve cultivars in certain specific traits [10]. Physical mutagens (X-rays, UV light, neutrons-alpha-beta particles, fast and thermal neutrons, especially gamma rays) are used more widely than chemical (ethyl methanesulfonate (EMS)) ones to artificially induce mutations (mutagenesis). Gamma-rays are widely used among the physical mutagens.

Thus, the main objective of this study was to generate new kenaf varieties with high biomass through mutation breeding. Also, it aimed to describe mutants in regards to their morphological, genetic and histological traits in comparison to the control variety, IT202801 line, in $\mathrm{M}_{2}$ irradiated generation.

\section{Materials and Methods}

\subsection{Seed Material and Experimental Location}

The kenaf seed variety used for the control was "IT202801", acquired from the National Agricultural Genetic Resources Center (NAGRC) in Korea. The experiment was conducted at the Agricultural Research and Extension Services in Iksan from 2017 to 2018. The average temperature of growth period was $21.3{ }^{\circ} \mathrm{C}$ from May to October.

\subsection{Screening of Mutants and Performance Evaluation}

A selection step of the elite mutants was done (Fig. 1). Approximately $100 \mathrm{~g}$ of kenaf seeds were irradiated with 200 Gy from ${ }^{60} \mathrm{Co}$ sources located in Korea Atomic Energy Research Institute (KAERI). Each of the 500 plants (1st generation, $\mathrm{M}_{1}$ ) was planted in 2017, grown to maturity in an upland field, and assigned numbers at harvest time. In 2018, the 200 plants of 2 nd generation $\left(\mathrm{M}_{2}\right)$ were planted and the mutants showing normal seed fertility were investigated on individual plants. The plant height, diameter, branch number, dry weight and seed weight were recorded for the isolated eight mutants and compared to the control plants, then later evaluated in five replications. Standard crop management practices were followed, such as the application of 15,10 , $10 / 1,000 \mathrm{~m}^{2}$ of N, P, K. Results were analyzed for analysis of variance (ANOVA) using SAS Enterprise Guide 4.2 (Statistical Analysis System, 2009, SAS Institute Inc., Cary, NC, USA). Also, comparison of means was done at $5 \%$ level of significance using Duncan's multiple range test (DMRT).

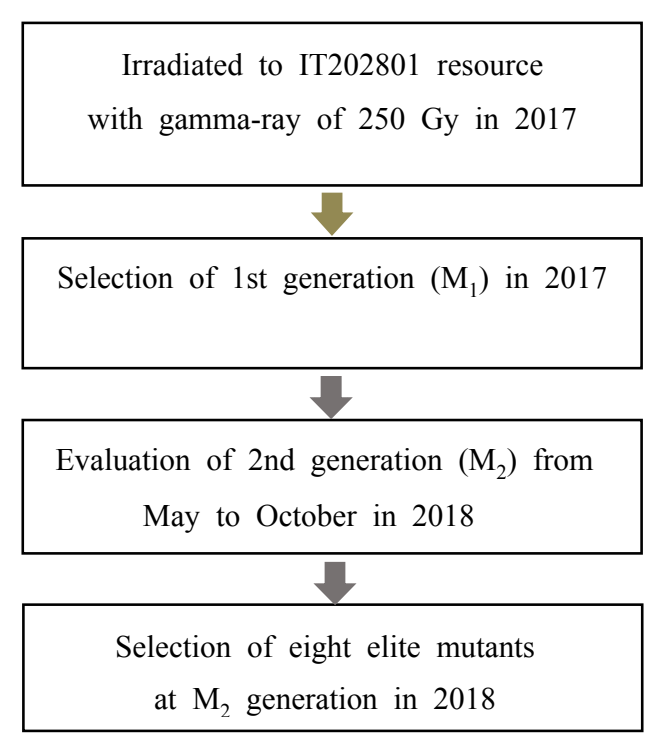

Fig. 1 Selection steps of kenaf elite mutants. 


\subsection{Polymerase Chain Reaction (PCR) Amplification and Gel Electrophoresis}

Genomic DNA was isolated using the DNA Extraction Kit (PowerPrep ${ }^{\mathrm{TM}}$, kogenebiotech, Seoul, Korea). Eighteen primers (Operon Technology) to generate reproducible random amplified polymorphic DNA (RAPD) bands were chosen. PCR amplification was done with the premix kit $\left(2 \mathrm{X}\right.$ TOPsimple ${ }^{\mathrm{TM}}$ PreMIX (aliquot)-Tenuto, enzynomics, Daejeon, Korea) of $20 \mu \mathrm{L}$ in combination with each DNA sample $(5 \mathrm{ng} / \mu \mathrm{L})$. The PCR reaction mix was preheated at $94{ }^{\circ} \mathrm{C}$ for 1 min followed by 45 cycles of $1 \mathrm{~min}$ denaturation at $94{ }^{\circ} \mathrm{C}, 30 \mathrm{~s}$ annealing at $36{ }^{\circ} \mathrm{C}$, and band elongation at $72{ }^{\circ} \mathrm{C}$ for $2 \mathrm{~min}$. After the last cycle, a final extension of $10 \mathrm{~min}$ at $72{ }^{\circ} \mathrm{C}$ was added to allow complete extension of all amplified fragments. The amplified product from each sample was separated electrophoretically on $1.2 \%$ agarose gel in a $1 \times$ TAE buffer at $120 \mathrm{~V}$ for $40 \mathrm{~min}$. Two molecular weight markers (100 bp DNA markers) were run alongside the RAPD reactions. The gels were stained with ethidium bromide, bands were observed and photographed by a gel documentation system (AE-9000 E-Graph, Atto, Tokyo, Japan).

\subsection{RAPD Analysis}

Gene alteration caused by gamma-ray induction has been detected using RAPD. Fragments were scored as 1 if present and 0 if absent. The scores were then pooled for constructing a single data matrix. This was used for comparing the frequencies of all polymorphic RAPD markers and estimating genetic distance. To estimate phylogeny among all plants, heuristic search to find parsimonious unweighted tree was carried out using nearest-neighbor-interchange (NNI) branch swapping program (PAUP 4.0 beta version) [11].

\subsection{Scanning Electron Microscope (SEM) Image}

The stems were air-dried for $48 \mathrm{~h}$ at $30{ }^{\circ} \mathrm{C}$. Each stem was then fastened using a nipper before cutting vertically to avoid mechanical injury for the vertical section filming. The specimens were air-dried for $20 \mathrm{~h}$ at $80{ }^{\circ} \mathrm{C}$ to shoot, then placed on an aluminum stub, and plated with gold using a gold ion sputtering device (Jeol, JFC-1100E, Fine Coat, Tokyo, Japan) at $10 \mathrm{~mA}$ for $400 \mathrm{~s}$. A mutant stem plated with gold was observed using an SEM (Jeol, JSM-5410LV, Tokyo, Japan) at $15 \mathrm{kV}$ condition [12].

\section{Results and Discussion}

\subsection{Plant Characteristics: Stem Color, Leaf Shape and Flowering Date}

Results on stem color, leaf shape and flowering date of the control and mutants were presented (Table 1). The stem color (red and light red) among the eight mutants was significantly observed when compared to the control in green. The leaf shapes of the kenaf were divided into two types: the control with entire, and the eight mutants with palmate leaves. Gamma-ray was effective in producing mutant. Similarly, a useful

Table 1 The different characteristics among various $\mathbf{M}_{2}$ generation kenaf mutants from vegetative to reproductive growth period.

\begin{tabular}{llll}
\hline Lines & Stem color & Leaf shape & Flowering date \\
\hline IT20 & Green & Entire & 7.23 \\
$\mathrm{M}_{2} \mathrm{IT} 20-1$ & Red & Palmate & 7.24 \\
$\mathrm{M}_{2} \mathrm{IT} 20-2$ & Red & Palmate & 7.24 \\
$\mathrm{M}_{2} \mathrm{IT} 20-3$ & Red & Palmate & 7.23 \\
$\mathrm{M}_{2} \mathrm{IT} 20-4$ & Red & Palmate & 7.23 \\
$\mathrm{M}_{2} \mathrm{IT} 20-5$ & Red & Palmate & 7.25 \\
$\mathrm{M}_{2} \mathrm{IT} 20-6$ & Red & Palmate & 7.24 \\
$\mathrm{M}_{2} \mathrm{IT} 20-7$ & Light red & Palmate & 7.24 \\
$\mathrm{M}_{2} \mathrm{IT} 20-8$ & Light red & Palmate & 7.25 \\
\hline
\end{tabular}

In the lines, IT20 means the control; lines indicating from $\mathrm{M}_{2} \mathrm{IT} 20-1$ to $\mathrm{M}_{2} \mathrm{IT} 20-8$ are mutants of $\mathrm{M}_{2}$ generation. 
mutant through this technique was obtained by other studies for roselle and kenaf [7, 13]. Mutagen caused insertion or deletion of nitrogen base which led to serious genome damage [14]. Nine plants, including the control and eight mutants, had little difference in the number of flowering days from July 23 to July 25 .

\subsection{Plant Characteristics: Plant Height, Diameter,} Branch Number, Dry and Seed Weight

Fig. 2 shows the varying plant height by the treatment. In box plot analysis (Fig. 2a), the range of
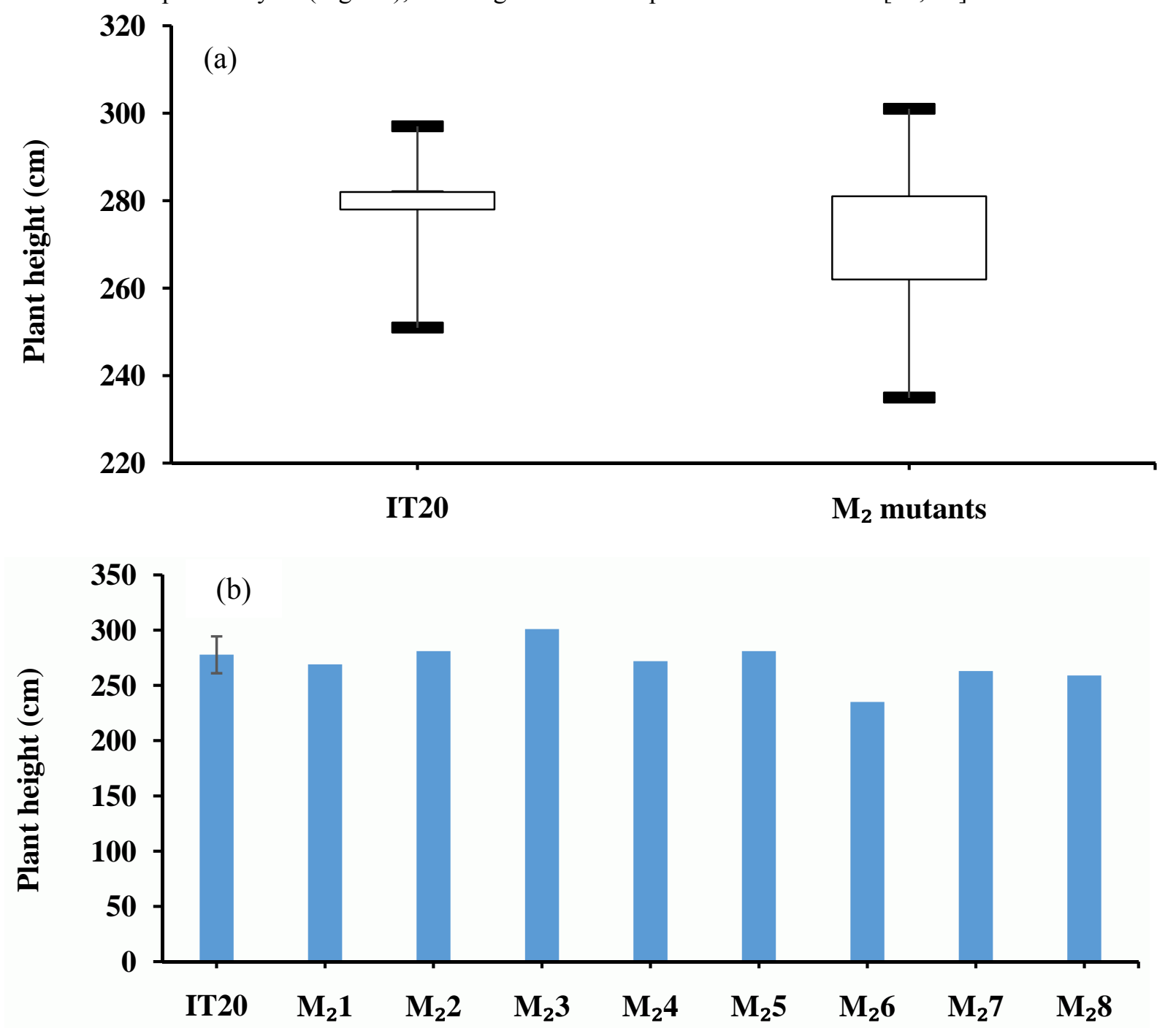

Fig. 2 Box plots (a) of plant height of IT20 (control) and $M_{2}$ eight mutants, and difference (b) of plant height compared with IT20 (control) and individual eight mutants in $170 \mathrm{~d}$ after planting.

Result of IT20 in Fig. $2 b$ is a mean \pm standard deviationof five replications. $M_{2} 1, M_{2} 2, M_{2} 3, M_{2} 4, M_{2} 5, M_{2} 6, M_{2} 7$ and $M_{2} 8$ indicate $\mathrm{M}_{2} \mathrm{IT} 20-1, \mathrm{M}_{2} \mathrm{IT} 20-2, \mathrm{M}_{2} \mathrm{IT} 20-3, \mathrm{M}_{2} \mathrm{IT} 20-4, \mathrm{M}_{2} \mathrm{IT} 20-5, \mathrm{M}_{2} \mathrm{IT} 20-6, \mathrm{M}_{2}$ IT20-7 and $\mathrm{M}_{2} \mathrm{IT} 20-8$ in Table 1, respectively. plant height was higher in the eight mutants of $\mathrm{M}_{2}$ generation than the control. However, no big difference was noted when comparing the control and the eight mutants individually (Fig. 2b). The result shows that gamma-ray did not greatly influence the plant height. No statistical analysis for the eight mutants was carried out because there was only one mutant in $\mathrm{M}_{2}$ generation. The result, however, was contrary to another study which showed that the kenaf and the amethyst flower mutants of the 2nd generation gave a significantly physiological difference in comparison to the control $[15,16]$. 
Fig. 3 shows the results on the effect of mutation to the diameter of the test plants. From the box plot (Fig. $3 a)$, the mutants were significantly different among each other in comparison with the control. Individual comparison of the control and the mutants indicated only one mutant $\left(\mathrm{M}_{2} 5\right)$ having a wide gap with the control and other mutants (Fig. 3b). In another study, a significant difference was also observed in the diameter between the control and mutants [13]; but the diameter in kenaf was not mutated [7], suggesting varietal difference as the cause.

Result from Fig. 4a indicated that the range of branch number of the mutants was different from the control. The means of branch number for the control was 20, while the mutants ranged from 10 to 31 (Fig. $4 b)$. There was a highly significant genotypic variation among the genotypes. Based on the results, mutant line $\mathrm{M}_{2} 5$ had the largest number of branches that is 31 , followed by mutant line $\mathrm{M}_{2} 6$ with 22 , and the lowest in mutant line $\mathrm{M}_{2} 3$ with 10 . This confirmed the results of previous studies on the variation in number of branches per plant [7, 8]. Also, number of branches per plant exhibited higher percentage of genetic advance [17]. It was indicated that this trait is under the control of additive gene action and would respond very well to continuous selection [18]. Also, mutagen influenced Rms1, Rms1 and Rms5 activities and caused variation on branching habit [19].

As to a dry weight range per plant, the mutants were significantly different in box plot analysis compared to the control (Fig. 5a). In individual comparison with the control, wide variation was observed in the kenaf mutants (Fig. 5b). The means of dry weight for the control is $332 \mathrm{~g} / \mathrm{plant}$, while mutants ranged from $572 \mathrm{~g} /$ plant to $1,008 \mathrm{~g} /$ plant (Fig. $5 b)$. Notably, the highest dry weight among mutant is line $\mathrm{M}_{2} 5$, followed by line $\mathrm{M}_{2} 3$, and the lowest was line $\mathrm{M}_{2} 1$. Overall, the mutant line $\mathrm{M}_{2} 5$ has more numerous
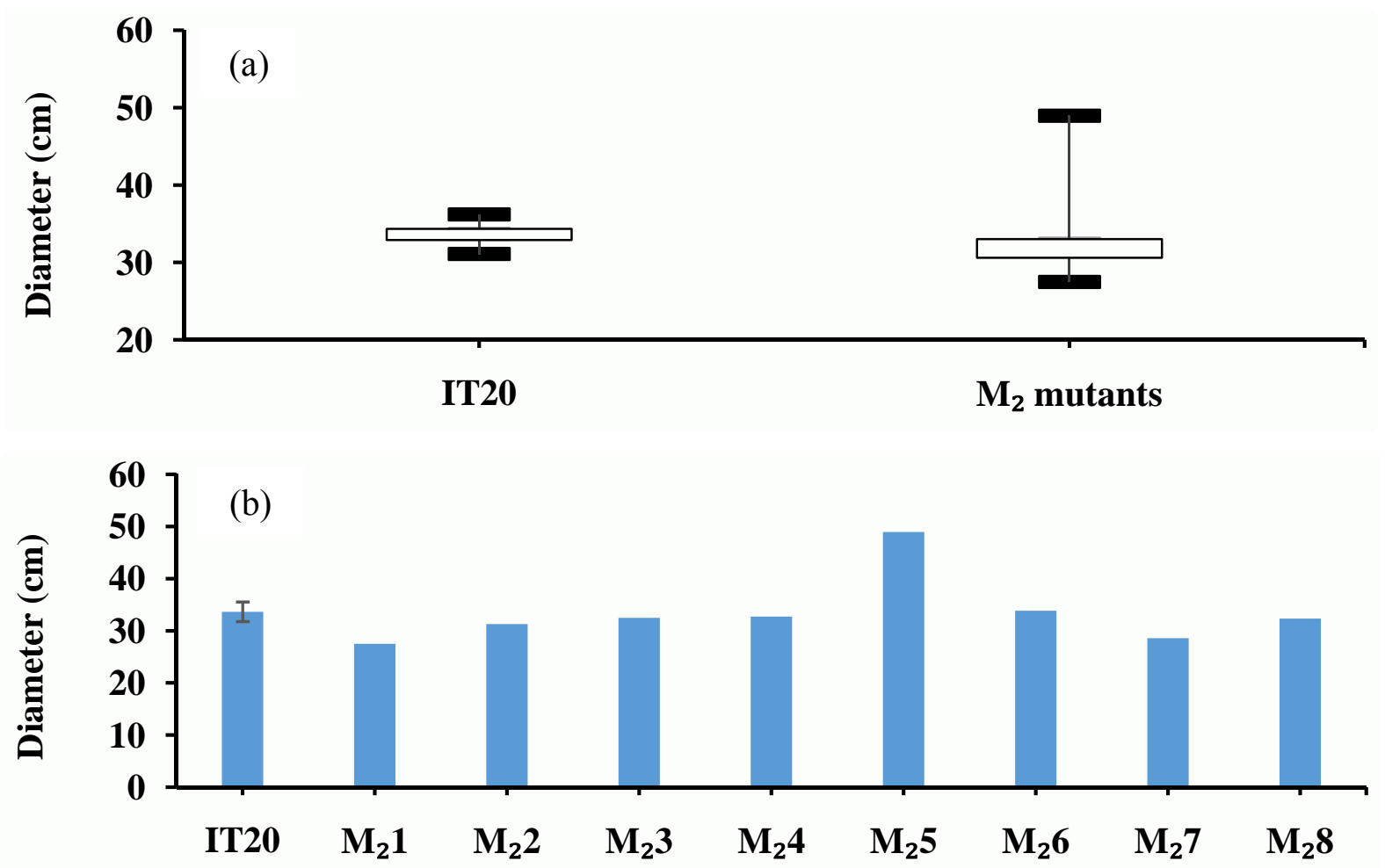

Fig. 3 Box plots (a) of diameter of IT20 (control) and $\mathrm{M}_{2}$ eight mutants, and difference (b) of plant height compared with IT20 (control) and individual eight mutants in $170 \mathrm{~d}$ after planting.

Result of IT2 0 in Fig. $3 b$ is a mean \pm standard deviation of five replications. $M_{2} 1, M_{2} 2, M_{2} 3, M_{2} 4, M_{2} 5, M_{2} 6, M_{2} 7$ and $M_{2} 8$ indicate $\mathrm{M}_{2}$ IT20-1, $\mathrm{M}_{2}$ IT20-2, $\mathrm{M}_{2}$ IT20-3, M IT20-4, $\mathrm{M}_{2} \mathrm{IT} 20-5, \mathrm{M}_{2}$ IT20-6, $\mathrm{M}_{2}$ IT20-7 and $\mathrm{M}_{2}$ IT20-8 in Table 1, respectively. 


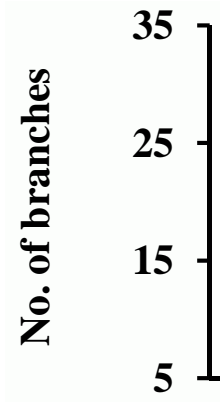

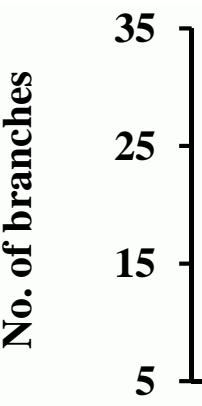

(a)

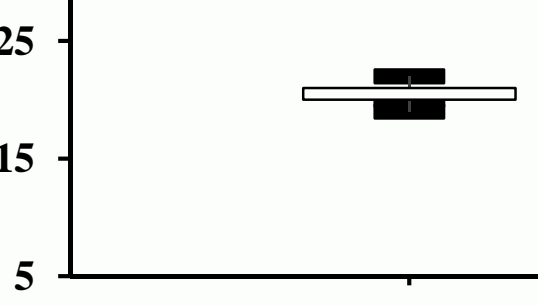

IT20

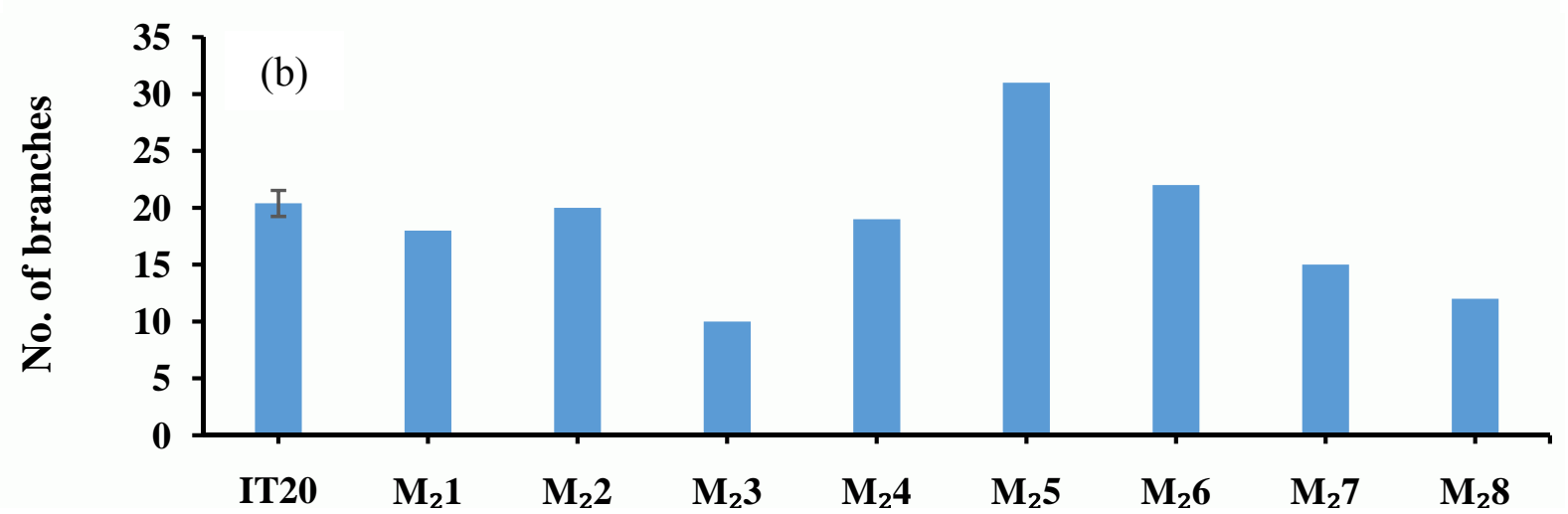

Fig. 4 Box plots (a) of branch numbers of IT20 (control) and $M_{2}$ eight mutants, and difference (b) of branch numbers compared with IT20 (control) and individual eight mutants in $170 \mathrm{~d}$ after planting.

Result of IT20 in Fig. 4b is a mean \pm standard deviation of five replications. $\mathrm{M}_{2} 1, \mathrm{M}_{2} 2, \mathrm{M}_{2} 3, \mathrm{M}_{2} 4, \mathrm{M}_{2} 5, \mathrm{M}_{2} 6, \mathrm{M}_{2} 7$ and $\mathrm{M}_{2} 8$ indicate $\mathrm{M}_{2} \mathrm{IT} 20-1, \mathrm{M}_{2} \mathrm{IT} 20-2, \mathrm{M}_{2} \mathrm{IT} 20-3, \mathrm{M}_{2} \mathrm{IT} 20-4, \mathrm{M}_{2} \mathrm{IT} 20-5, \mathrm{M}_{2} \mathrm{IT} 20-6, \mathrm{M}_{2} \mathrm{IT} 20-7$ and $\mathrm{M}_{2} \mathrm{IT} 20-8$ in Table 1, respectively.
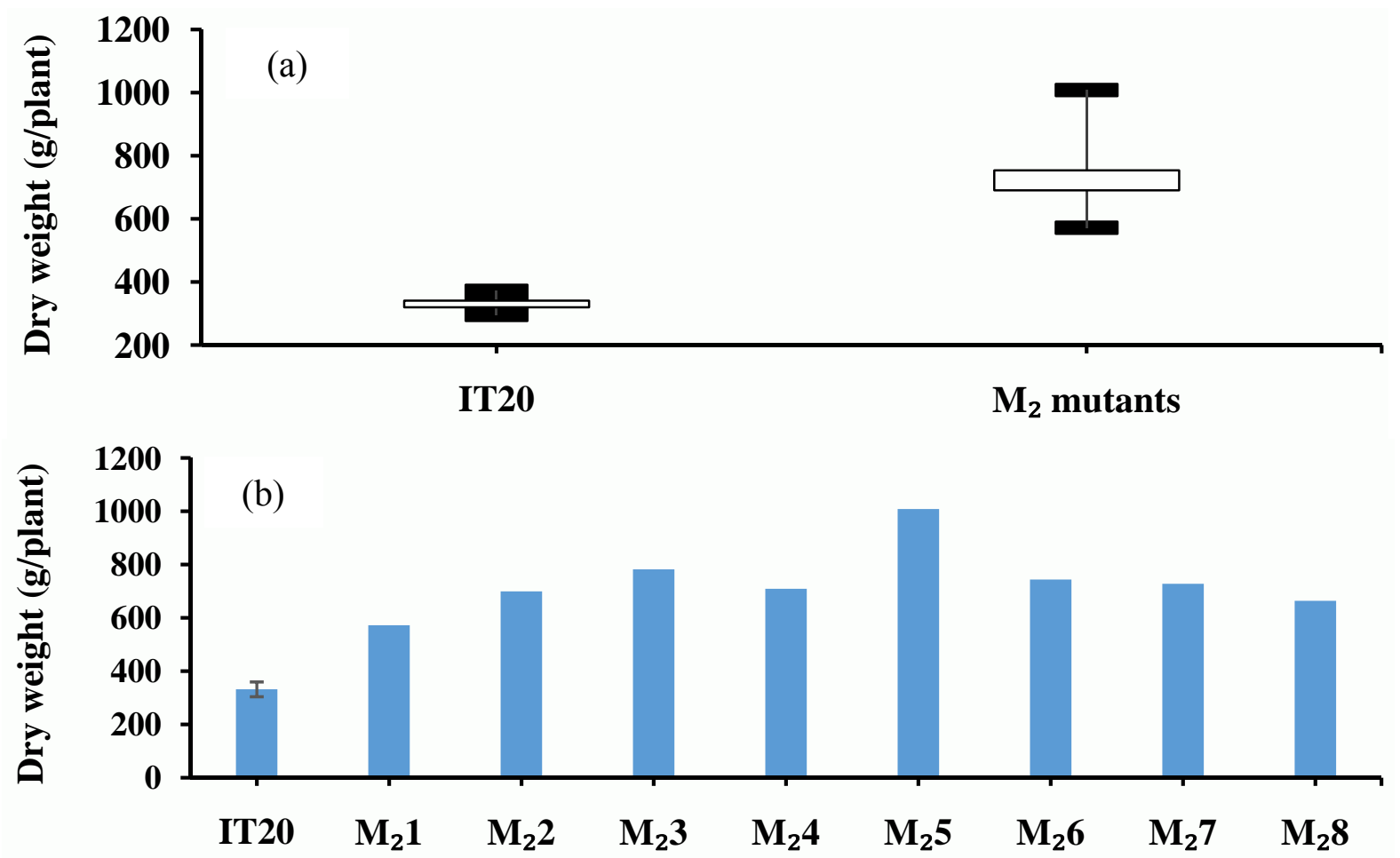

Fig. 5 Box plots (a) of dry weight of IT20 (control) and $M_{2}$ eight mutants, and difference (b) of dry weight compared with IT20 (control) and individual eight mutants in $170 \mathrm{~d}$ after planting.

Result of IT20 in Fig. $5 \mathrm{~b}$ is a mean \pm standard deviation of five replications. $\mathrm{M}_{2} 1, \mathrm{M}_{2} 2, \mathrm{M}_{2} 3, \mathrm{M}_{2} 4, \mathrm{M}_{2} 5, \mathrm{M}_{2} 6, \mathrm{M}_{2} 7$ and $\mathrm{M}_{2} 8$ indicate $\mathrm{M}_{2}$ IT20-1, $\mathrm{M}_{2}$ IT20-2, $\mathrm{M}_{2}$ IT20-3, $\mathrm{M}_{2}$ IT20-4, $\mathrm{M}_{2}$ IT20-5, $\mathrm{M}_{2}$ IT20-6, $\mathrm{M}_{2}$ IT20-7 and $\mathrm{M}_{2}$ IT20-8 in Table 1, respectively. 
leaves than the others. Some authors [20, 21] likewise noted significant effect on dry weight for the mutants when compared to the control. Another study [13] reported that the weight of dry calyx in mutant was also increased as compared with the parent line. However, there were also studies with results in contrary [22]. Previous report on soybean showed a strong association between increase of leaf area growth and improvement of plant productivity [23].

Fig. 6 shows the analysis of seed weight per plant between the control and the mutants. In box plot analysis, the range of seed weight was heavier in the mutants than the control (Fig. 6a). Individual comparison of the control and the mutants showed that mutant line $\mathrm{M}_{2} 5$ had significant variation (Fig. $6 \mathrm{~b})$. The means of seed weight for the control is 22.9 $\mathrm{g} / \mathrm{plant}$, while mutants ranged from $23 \mathrm{~g} /$ plant to 200 g/plant (Fig. 6b). Among the mutants, the line $\mathrm{M}_{2} 6$ with weight of $200 \mathrm{~g}$ had the highest mean and the line $\mathrm{M}_{2} 8$ with $23 \mathrm{~g}$ weight had the lowest mean. Results indicated that most of the new mutants showed better performance than the control with the significant variations in weight of seeds per plant, with these result confirmed in other studies [13, 24].

\subsection{Genetic Diversity of Genotypes: RAPD Analysis and Phylogenetic Tree}

RAPD analysis was done to detect genetic diversity at the DNA level. Eighteen primers were selected based on their ability to generate reproducible bands. Of the 18 primers, six primers showed monomorphic bands, while 12 primers produced specific polymorphic bands in the mutants (Fig. 7a). Primer OPA11 generated the highest number of bands whereas the OPB2 yielded the least number of bands with its absence for the control (Fig. 7a). The RAPD analysis produced a genetic diversity of $72.7 \%$ within the genotypes used. The result of the RAPD technique
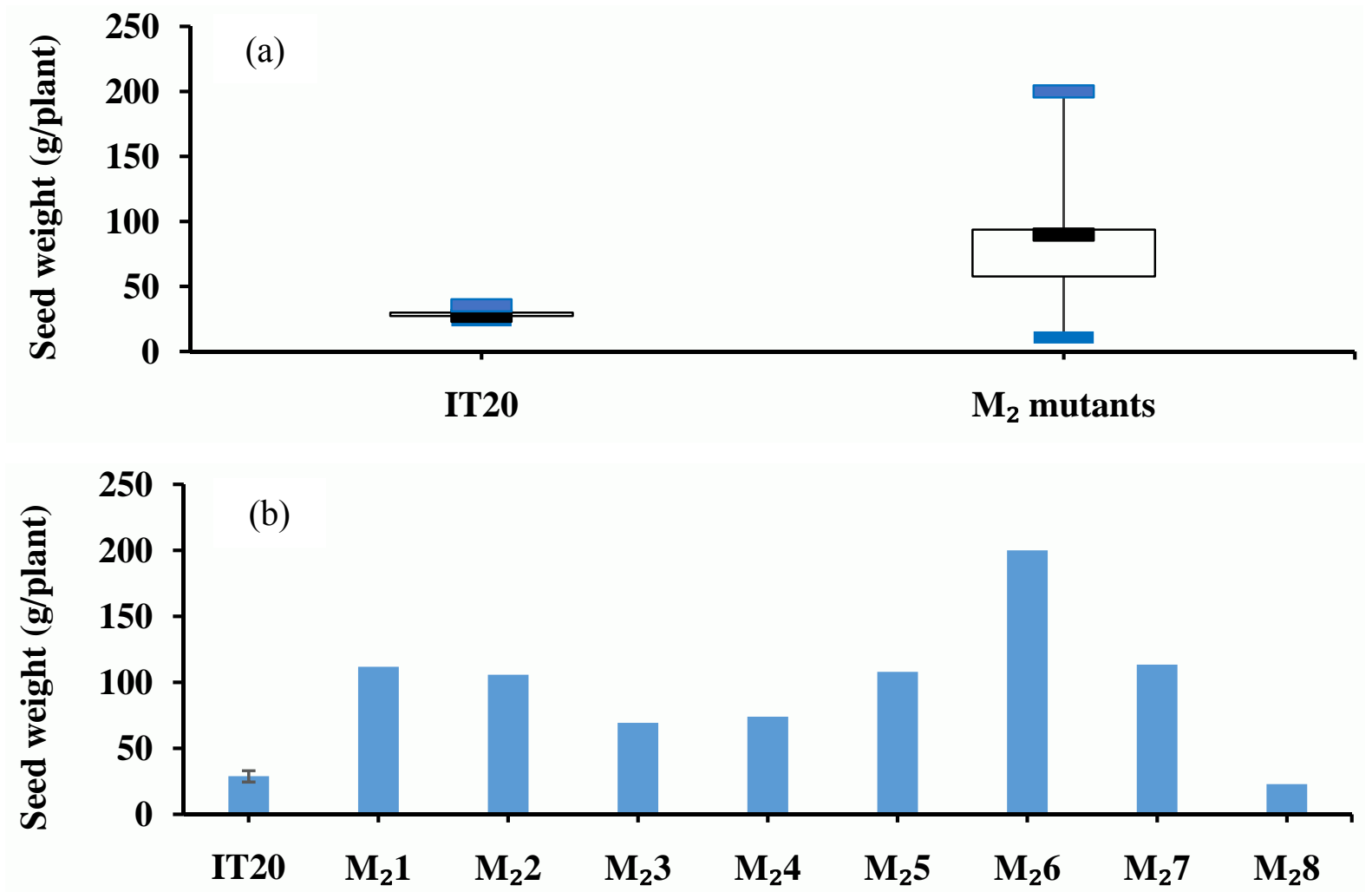

Fig. 6 Box plots (a) of seed weight of IT20 (control) and $M_{2}$ eight mutants, and difference (b) of seed weight compared with IT20 (control) and individual eight mutants in $170 \mathrm{~d}$ after planting.

Result of IT20 in Fig. $6 \mathrm{~b}$ is a mean \pm standard deviation of five replications. $\mathrm{M}_{2} 1, \mathrm{M}_{2} 2, \mathrm{M}_{2} 3, \mathrm{M}_{2} 4, \mathrm{M}_{2} 5, \mathrm{M}_{2} 6, \mathrm{M}_{2} 7$ and $\mathrm{M}_{2} 8$ indicate $\mathrm{M}_{2}$ IT20-1, $\mathrm{M}_{2}$ IT20-2, $\mathrm{M}_{2} \mathrm{IT} 20-3, \mathrm{M}_{2} \mathrm{IT} 20-4, \mathrm{M}_{2} \mathrm{IT} 20-5, \mathrm{M}_{2} \mathrm{IT} 20-6, \mathrm{M}_{2} \mathrm{IT} 20-7$ and $\mathrm{M}_{2}$ IT20-8 in Table 1, respectively. 
demonstrates that it is capable of revealing nuclear DNA variation in kenaf genotypes. A similar study on genetic diversity of 21 variants of kenaf recorded $68.18 \%$ polymorphism [25].

The genetic distance was calculated using NNI branch swapping program to clarify the genetic relationships. The dendrogram grouped the populations into two main clusters (Fig. 7b), which revealed a wide range of genetic identity. The control with mutant lines $\mathrm{M}_{2} 1$ and $\mathrm{M}_{2} 2$ were clustered in one group and remaining genotypes were in the other group. The first group was divided into two subgroups. The second group consisted of four subgroups. Based on the result, a degree of genetic variation existed between the control and the mutants, thus indicating that gamma-ray treatment could produce polymorphic regions in the kenaf mutant. Similar results were reported in previous studies $[25,26]$.

\subsection{Comparison of SEM}

Histological alteration caused by gamma-ray was detected using SEM image (Fig. 8). The SEM image of stem tissue between the control and the mutant line $\mathrm{M}_{2} 5$ differed significantly. In particular, the vessels (v) in core fiber of the mutant were significantly bigger compared to that of the control (Fig. 8b) attributed to the mutation induced by gamma-ray. The difference of the SEM image for the control and mutants was consistent with the previous report [27].

From all the experimental results, the selection for isolating the elite mutants was highly probable for high biomass production.
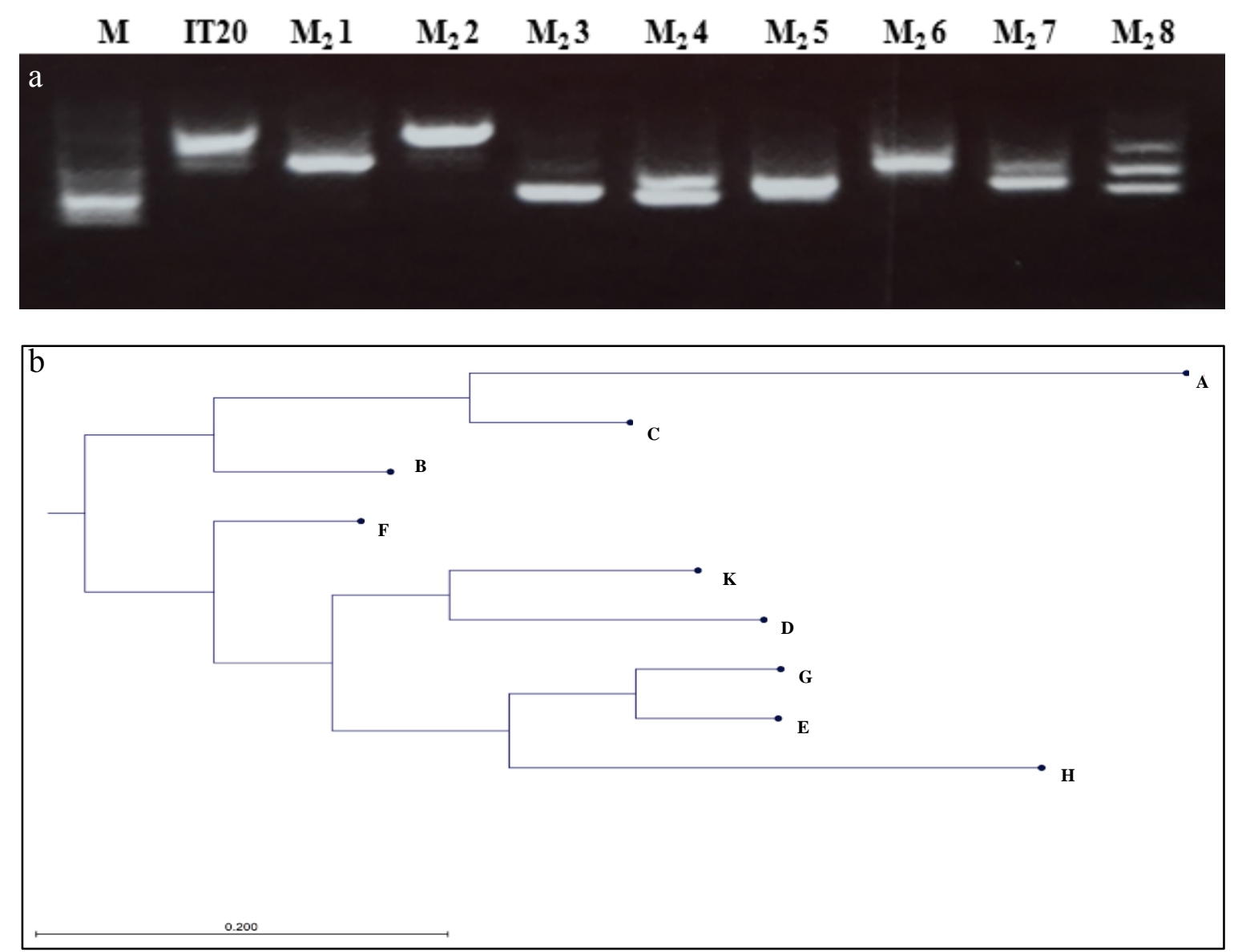

Fig. 7 The RAPD profiles using primer OPA18 (a) for IT20 (control) and eight mutants; phylogenetic tree (b) of IT20 (control) and eight mutants.

$\mathrm{M}_{2} 1, \mathrm{M}_{2} 2, \mathrm{M}_{2} 3, \mathrm{M}_{2} 4, \mathrm{M}_{2}$ 5, $\mathrm{M}_{2} 6, \mathrm{M}_{2}$ and $\mathrm{M}_{2} 8$ indicate $\mathrm{M}_{2}$ IT20-1, $\mathrm{M}_{2}$ IT20-2, $\mathrm{M}_{2}$ IT20-3, $\mathrm{M}_{2}$ IT20-4, $\mathrm{M}_{2}$ IT20-5, M 2 IT20-6, M IT20-7 and $\mathrm{M}_{2}$ IT20-8 in Table 1, respectively. M: 100 bp molecular markers. 


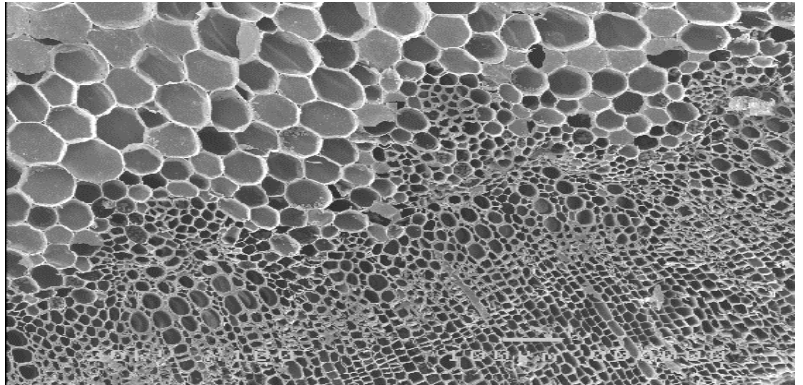

(a)

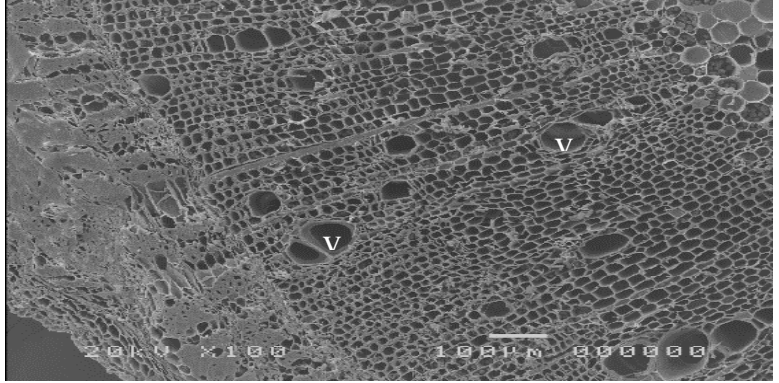

(b)

Fig. 8 Histological analysis of IT20 (control, a) and mutant line $M_{2} 5$ (b) by scanning electron microscope (SEM) image. There are many bigger vessels (v) in the mutant than the control. Bar $=100 \mu \mathrm{m}$.

\section{Conclusions}

To develop new superior mutants compared to its parent, gamma-induced mutation is the fastest and quickest method. Screening and selection of desired mutants were the most critical step in early generation. Assessment of important morphological traits in $\mathrm{M}_{2}$ progeny is common.

The morpho-agronomic traits, genetic diversity and histological characteristic were used to identify various attributes of these new mutants developed from IT202801 line as the control. The mutants exhibited significant differences for plant characteristics. Some mutants showed better performance in all eight studied parameters compared to the control, IT202801 line. Among morpho-agronomic traits, the dry weight of the mutants was significantly different from the control highly suggesting that gamma irradiation could be effective for inducing mutagenesis. Notably, the mutant line $\mathrm{M}_{2} 5$ presented better performance than this parent IT202801 line based on four parameters of plant characteristics such as diameter, number of branches per plant, dry weight per plant, seed weight per plant, while plant height was comparable with the control.

The variation could be seen as a manifestation of environmental response, so a genetic variation of DNA level was estimated to avoid this effect. From the RAPD analysis, a wide genetic diversity in terms of DNA level was obtained from $\mathrm{M}_{2}$ progenies in comparison with the control. Phylogenetic cluster analysis on RAPD profiles in kenaf IT202801 and $\mathrm{M}_{2}$ mutants shows that the genotypes were classified into six groups: kenaf IT202801 parental line with two mutants fell into the same group, and another group accounted for the highest number of genotypes. Histological analysis showed that the mutant line $\mathrm{M}_{2} 5$ had discriminatory mutation when compared to the control.

Finally, the selection in $\mathrm{M}_{2}$ generations can increase the probability of identifying superior mutations, while the mutant line $\mathrm{M}_{2} 5$ can be useful as a resource for high biomass production in Korea.

\section{References}

[1] Yazan, L. S., Foo, J. B., Ghafar, S. A. A., Chan, K. W., Tahir, P. M., and Ismail, M. 2011. "Effect of Kenaf Seed Oil from Different Ways of Extraction towards Ovarian Cancer Cells." Food Bioprod. Process 89: 328-32.

[2] Behmaram, R., Saleh, G., Foroughi, M., Noori, Z., Panandam, J. M., and Harun, J. 2014. "Genetic Control of Fiber Yield and Quality in Kenaf (Hibiscus cannabinusL.)." Iranian Journal of Genetics and Plant Breeding 3 (1): 31-41.

[3] Danalatos, N. G., and Archontoulis, S. V. 2010. "Growth and Biomass Productivity of Kenaf (Hibiscus cannabinus L.) under Different Agricultural Inputs and Management Practices in Central Greece." Ind. Crop Prod. 32: 231-40.

[4] Dauda, S. M., Desa, A., Abdan, K., and Jamarei, O. 2013. "Performance Evaluation of a Tractor Mounted Kenaf Harvesting Machine.” Academic Res. Int. 4: 70-81.

[5] Kang, C. H., Lee, I. S., Go, D. Y., Kim, H. J., and Na, Y. E. 2018. "The Growth and Yield Differences in Kenaf (Hibiscus cannabinus L.) in Reclaimed Land Based on the Physical Types of Organic Materials." Korean J. Crop Sci. 63 (1): 64-71.

[6] Lee, I. S., Kang, C. H., Kwon, S. J., and Na, Y. E. 2018. "Effects of PEG Priming and Treatment on Kenaf 
(Hibiscus cannabinus L.) Seed Germination.” Journal of Agricultural Science and Technology B 8: 278-89.

[7] Ryu, J. H., Kwon, S. J., Ahn, J. W., Kim, S. H., Lee, S. Y., Kim, J. B., Jo, Y. D., Ha, B. K., and Kang, S. Y. 2018. "Development of a Stem-Color Mutant Kenaf (Hibiscus cannabinus L.) Cultivar, 'Jeokbong', and Analysis of Its Functional Compounds." Horticultural Science and Technology 36 (1): 77-84.

[8] Kumar, V., Sharma, A. K., Singh, V. P., and Kumar, M. 2009. Induced Plant Mutations in the Genomics Era: Characterization of Pre-breeding Genetic Stocks of Urdbean (Vigna mungo L. Hepper) Induced through Mutagenesis. Vienna: International Atomic Energy Agency.

[9] Shu, Q. Y., Forster, B. P., and Nakagawa, H. 2012. Molecular Techniques and Methods for Mutation Detection and Screening in Plants: Plant Mutation Breeding and Biotechnology. Oxford shire: Springer International Publishing AG.

[10] Kurobane, I., Yamaguchi, H., Sander, C., and Nilan, R. 1979. "The Effects of Gamma Irradiation on the Production and Secretion of Enzymes and Enzymatic Activities in Barley." Env. Exp. Botany 19: 75-84.

[11] Swofford, D. L. 1998. Phylogenetic Analysis Using Parsimony: Version 4. Massachusetts: Sinauer Associate.

[12] Bednorz, L., and Czarna, A. 2008. "SEM and Stereoscope Microscope Observations on the Seeds of Some Ornithogalum (Hyacinthaceae) Species.” Biologia 63 (5): 642-6.

[13] Osman, M., Golam, F., Saberi, S., Majid, N. A., Nagoor, N. H., and Zulqarnain, M. 2011. "Morpho-Agronomic Analysis of Three Roselle (Hibiscus sabdariffa L.) Mutants in Tropical Malaysia." Australian Journal of Crop Science 5 (10): 1150-6.

[14] Greene, E. A., Codome, C. A., and Taylor, N. E. 2003. "Spectrum of Chemically Induced Mutations from a Large-Scale Reverse-Genetic Screen in Arabidopsis." Genetics 164: 731-40.

[15] Masita, R., and Arumingtyas, E. L. 2014. "Drought Resistance Variation of Mutant of Kenaf KR11 Based on Proline Accumulation." Natural B 2 (3): 266-70.

[16] Hoda, E. E., and Gehan, G. M. 2014. "Induction of Mutations in Browallia speciose Using Sodium Azide and Identification of the Genetic Variation by Peroxidase Isozyme." African Journal of Biotechnology 13 (1): 106-11.

[17] Malek, M. A., Rafii, M. Y., Afroz, M. S. S., Nath, U. K., and Mondal, M. M. A. 2014. "Morphological Characterization and Assessment of Genetic Variability, Character Association, and Divergence in Soybean Mutants.” The Scientific World Journal 2014: 1-12.

[18] Panse, V. G. 1957. "Genetics of Quantitative Characters in Relation to Plant Breeding." Indian Journal of Genetics and Plant Breeding 17: 318-28.

[19] Arumingtyas, E. L., Mastuti, R., and Indriyani, S. 2010. "The Role of AUX1 Gene and Plant's Auxin Content to the Branching Phenotype of Kenaf (Hibiscus cannabinus L.)." Physiol. Mol. Biol. Plant 16 (1): 93-8.

[20] Al-Amier, H., Toaima, N., Mansour, B. M. M., El Hela, A. A., Sastry, K. S., and Craker, L. 2006. "Use of Mutations to Improve Essential Oil Yield and Constituency in Pennyroyal." Journal of Herbs, Spices \& Medicinal Plants 11: 91-101.

[21] Joshi, R., Prashat, G. R., Sharma, P. C., and Singla-Pareek, S. L. 2016. "Physiological Characterization of Gamma-Ray Induced Mutant Population of Rice to Facilitate Biomass and Yield Improvement under Salinity Stress." Indian Journal of Plant Physiology 21 (4): 545-55.

[22] Beveridge, C. A., Ross, J. J., and Murfet, I. C. 1994. "Branching Mutant rms-2 in Pisum sativum." Plant Physiol. 104 (3): 953-9.

[23] Koester, R. P., Skoneczka, J. A., Cary, T. R., Diers, B. W., and Ainsworth, E. A. 2014. "Historical Gains in Soybean (Glycine max Merr.) Seed Yield Are Driven by Linear Increases in Light Interception, Energy Conversion, and Partitioning Efficiencies." J. Exp. Bot. 65: 3311-21.

[24] Banerjee, R., Sinha, M. K., and Roy, M. K. G. 1988. "Correlation and Path Coefficient Analysis of Yield Components in Hibiscus sabdariffa L.” Jute Development J. 8: 643-5.

[25] Haque, M., Biswas, T., Islam, M., and Hossain, M. 2017. "In Vitro Regeneration and PCR-RAPD Based Detection of Somaclonal Variation in Kenaf (Hibiscus cannabinus)." Progressive Agriculture 28 (2): 100-8.

[26] Mullainathan, L., Sridevi, A., Umavathi, S., and Sanjai Gandhi, E. 2014. "Genetic Variation in Mutants of Chilli (Capsicum annum) Revealed by RAPD Marker." International Letters of Natural Sciences 11: 1-8.

[27] Matsushima, R., Maekawa, M., Fujita, N., and Sakamoto, W. 2010. "A Rapid, Direct Observation Method to Isolate Mutants with Defects in Starch Grain Morphology in Rice.” Plant Cell Physiol. 51 (5): 728-41. 